V. 2, n. 3, Set. / dez, 2019

\title{
REVISTA ENSINO DE GEOGRAFIA
} (RECIFE)

\section{REFORMAS EDUCATIVAS NO BRASIL E NA ARGENTINA: ENSAIOS DE HISTÓRIA COMPARADA DA EDUCAÇÃO (1820-2000). SÃO PAULO: CORTEZ, 2009}

\author{
Natália Lampert Batista \\ Doutora em Geografia pelo - PPGGEO/UFSM \\ natilbatista3@gmail.com \\ ORCID Id: http://orcid.org/0000-0002-1884-2340
}

Cesar De David

Professor Associado da Universidade Federal de Santa Maria cdedavid209@gmail.com

ORCID Id: http://orcid.org/0000-0003-0872-9181

Resenha recebida em 05/10/2019 e aceita em 27/01/2020

O livro Reformas educativas no Brasil e na Argentina: ensaios de história comparada da educação (1820-2000) foi organizado pelo professor Adrián Ascolani de História Sociopolítica, da Universidad Nacional do Rosario, e pela professora Diana Gonçalves Vidal da Faculdade de Educação, da Universidade de São Paulo. O livro conta com sete capítulos escritos por variados autores que permite contextualizar e comparar a história da educação nos dois países, tornando-se uma importante referência quando se trata do entendimento das dinâmicas sociais e espaciais do Cone Sul, que é o foco de minha pesquisa de pós-doutorado.

O livro apresenta o resultado de uma pesquisa oriunda de um projeto binacional intitulado A constituição e reforma dos sistemas educativos no Brasil e na Argentina: histórias comparadas (1820-1980) com financiamento da Coordenação de Aperfeiçoamento de Pessoal de Nível Superior (CAPES), no Brasil, e do Ministerio de Educación, Cultura, Ciencia y Tecnología (SECyT/MINCyT), na Argentina. A abordagem central do trabalho perpassa pela ideia de que as histórias dos dois países estão conectadas e, portanto, sua aproximação pode gerar provações e respostas teórico-práticas para a educação nos dois países, pois “[...] o 
desenvolvimento da escola tanto no Brasil como na Argentina se coadunava ao movimento internacional da escolarização da massa" (VIDAL; ASCOLARI, 2009, p. 08) e a organização da educação no Brasil e na Argentina passou por muitos intercâmbios na produção de um referencial local.

Para essa resenha, traçaremos um breve apanhado dos capítulos propostos pelos diferentes autores, bem como buscaremos interpretar criticamente o conteúdo do livro aqui resenhado.

O primeiro capítulo do livro As reformas educativas como objeto de pesquisa em História Comparada da Educação na Argentina e no Brasil foi escrito por Silvina Gvirtz, Diana Vidal e Maurilane Biccas. As três autoras buscam discutir o entendimento de reforma educativa, sem, no entanto, acomodar todas as acepções do conceito devido à diversidade de abordagens e de autores se que debruçam sobre o tema e pelas inúmeras disputas imbricadas na temática. Inicialmente, as pesquisadoras apresentam pressupostos teóricos sobre as reformas educativas, destacando que etimologicamente a palavra deriva de devolver a forma, tornar melhor. "A reforma altera, substitui as deliberações ou determinações inseridas no despacho ou na sentença” (VIDAL; ASCOLARI, 2009, p. 16). Nesta Perspectiva, "[...] o termo reforma tem sido utilizado para designar um ato político ou legislativo na tentativa de alterar, corrigir e produzir mudanças sempre em uma perspectiva de aprimoramento" (VIDAL; ASCOLARI, 2009, p. 17). Por outro lado, podem-se identificar elementos que leva a um entendimento de reforma como parte de um processo de regulação social e que nem toda a mudança é uma reforma.

Para que uma reforma aconteça, segundo as autoras, é preciso que exista um projeto de reforma que tenha certa amplitude sobre as realidades e representações coletivas das escolas, bem como é necessário que essa reforma suscite um amplo debate coletivo. "A reforma é, assim, um processo social complexo, escalonado no tempo, e que envolve uma pluralidade de atores no debate social e pedagógico" (VIDAL; ASCOLARI, 2009, p. 18) e que não pode ser confundida com o marketing para sua implementação. Elas alteram desde o âmbito mais global do sistema educativo como também tem interferência direta sobre o currículo e a formação docente.

Após essa discussão mais teórica sobre a conceituação de reforma, as autoras abordam os Alcances e limites de uma história comparada das reformas educativas no Brasil e na Argentina, analisando inúmeras pesquisas sobre a história da educação nos dois países e destacando A década de 1880: a reforma como categoria histórica onde enunciam e discutem 
a reforma ocorrida no Brasil e na Argentina e as múltiplas transformações fomentadas neste período. As autoras destacam ainda que a concepção de Estado Educador, emergente sob o contundente discurso de Rui Barbosa, no Brasil, que destacava a penúria educativa, e encontrava eco na legislação argentina. Assim, o capítulo envolve uma leitura conceitual e comparada da abordagem sobre reforma no Brasil e na Argentina, buscando inverter e questionar as lentes historiográficas.

O segundo capítulo Pela classe, pelo livro: a fundação de uma História da Educação para professores, no Brasil e na Argentina, escrito por Adrián Ascolani e José Gonçalves Gondra, traz um diagnóstico da expansão e da diversificação da História da Educação sob o olhar de diferentes autores. Os pesquisadores realizam a análise de dois manuais, publicados no Brasil e na Argentina, respectivamente, a saber: Manuais de Afrânio Peixoto (1933) e de Ethel Manganiello e Violeta Bregazzi (1953). Para eles, "Ambas as obras tiveram uma inspiração idealista e espiritualista similar, não obstante as condições de sua emergência e êxito" (VIDAL; ASCOLARI, 2009, p. 44). Com relação ao seu estilo, os autores destacam que realizaram uma análise diferenciada privilegiando "[...] a história intelectual e biográfica no caso brasileiro e a história do currículo no caso argentino" (VIDAL; ASCOLARI, 2009, p. 44). Para isso, o capítulo é subdividido em Brasil: uma história da educação para a reforma e Argentina: um texto para a reforma espiritualista do magistério onde se aprofunda o debate e a interpretação histórica dos dois manuais, bem como se apresenta a complexa relação entre ambos.

No livro argentino a ideologia pairava sobre a fiel imutabilidade. Já os juízos de valor eram recorrentes no texto brasileiro com um evidente compromisso com as noções reformistas da época. Os dois manuais visavam destacar que o professor deveria estar inserido no processo, mas ao mesmo tempo deveria seguir as lições para uma boa atuação, baseandose em uma enciclopédia, uma espécie de dicionário e o que, hoje, poderíamos chamar de planos de aula ou sequências didáticas, elaborados com intuito de direcionar as lições escolares (VIDAL; ASCOLARI, 2009).

O terceiro capítulo A educação e a questão da construção de identidades modernas no século XXI: os casos da Argentina e do Brasil, escrito por Luciano Mendes de Faria Filho e Pablo Pineau, destaca que as nações latino-americanas têm sua constituição vinculada à herança colonial, tendo como importante papel na nova ordem mundial como fornecedoras de matérias-primas para as economias centrais. Segundo os autores, a manutenção ou o 
questionamento dessas características perpassam pela educação e pela construção de identidades político-culturais que são oriundas de muita luta e de muita resistência.

Para iniciar o debate, há a discussão sobre Educação do povo e modernização elitista: instrução pública e cultura política na Argentina no século XIX e posteriormente se abarca a Educação do povo e autoritarismo das elites: instrução pública e cultura política na Brasil do século XIX. A abordagem dos autores ressalta a ideia de que muitas reformas e políticas educacionais nos dois países, neste período, visavam "civilizar os bárbaros", isto é, os povos nativos, e "educar as elites", ou seja, predominava (e predomina em muitos contextos) uma educação excludente, seletiva e contraditória, uma educação instrutiva para alguns e crítica para outros.

Assim, "Fazer a crítica radical e contundente da mesma deveria ser um compromisso de todos aqueles que querem fazer uma outra história" (VIDAL; ASCOLARI, 2009, p. 110). Os autores, então, concluem que:

[...] a ideia de incorporação, de forma subalterna, das camadas populares da República (no caso da Argentina) ou ao Império (no caso do Brasil), deu lugar a um conjunto de ações, as quais tiveram no investimento (discursivo) na educação um de seus pontos mais fortes. Educar, instruir, civilizar... Eram ideias continuamente mobilizadas nos mais diferentes discursos que visavam criar, no horizonte de expectativas de nossas jovens nações, um futuro grandioso e forte, mesmo que isso tivesse que ser feito aniquilando ora inimigos internos, ora inimigos externos, como muitas vezes se fez no século XIX. (VIDAL; ASCOLARI, 2009, p. 101).

Em Formação do Estado Nacional e constituição de corpos docentes (1820-2000: profissionalização da docência no Brasil e na Argentina em perspectiva comparada, Alessandra Frota Martinez de Schueler e Myriam Southwell abordam construção do entendimento do papel de educar e algumas das inúmeras funções da profissão docente. Destacam que "Essas funções consolidaram também uma imagem social acerca do que é um docente, do que se deve esperar dele e sobre quais são seus atributos" (VIDAL; ASCOLARI, 2009, p. 115). As autoras remontam a história da profissão-professor nos dois países de forma pontual e comparada, articulando-os com o contexto histórico em cada um, bem como destacando que o "normalismo" se converteu em uma matriz de pensamento que orientou a docência nesses países por gerações. A expressão remete a “[...] posições contraditórias, que lutaram para dominar e se constituir como hegemônicas no campo da discursividade sobre a formação docente" (VIDAL; ASCOLARI, 2009, p. 152). Segundo as autoras questões como a organização da entrada e da saída das escolas, dos recreios, da disciplina e da disposição na sala de aula, do uso do tempo e do espaço e da avaliação nasceram desse contexto e se "[...] 
encarnavam na formação do professor como vanguarda da cultura" (VIDAL; ASCOLARI, 2009, p. 153).

Por outro lado, no capítulo é abordado que a profissionalização docente tem sido objeto de inúmeros debates e campo de disputa, colocando-se em uma complexa amálgama de problemáticas e temáticas. Essa abordagem foi central nas reformas de 1990. "A identidade profissional dos professores se definiu sob a tutela do Estado Nacional num processo que supunha a consequente interdependência dos interesses das próprias comunidades locais e a definição de qualidades, virtudes e capacidades que deveriam se ajustar ao projeto nacional" (VIDAL; ASCOLARI, 2009, p. 153) e isso faz com que essa profissionalização se torne regulada e siga uma norma estabelecida e uma trajetória desejada.

O quinto capítulo, proposto por Angela Aisenstein e Heloísa Helena Pimenta Rocha e intitulado A escolarização dos corpos entre fundações e reformas: Brasil e Argentina (18801940) contextualiza a educação individual dos corpos, passando por uma série de posturas comportamentais e atitudinais que deveriam ser instituídas por via da educação e, por conseguinte, serem aceitas na sociedade.

\begin{abstract}
Subjacente a essa concepção de que o corpo expressa o homem profundo, o homem interior, reside à crença de que é possível formar ou reformar suas disposições íntimas, ajustando corretamente as manifestações do corpo. É, pois, sobre o corpo que as normas de civilidade incidem com maior rigor (Revel, 1992; Foucault, 1987). Assim, adestrar o corpo, menos que negá-los, passa a fazer parte do processo formativo ou humanizador, o qual não pode prescindir, para sua eficácia, da conversão da rede de imposições sociais em autoimposições. (VIDAL; ASCOLARI, 2009 , p. 163 , sic.).
\end{abstract}

Assim, uma série de "inovações pedagógicas” é imposta para sanar essa demanda. As escolas jesuítas incorporam os bons costumes, pois "é preferível aprender na escola que nas academias militares" (VIDAL; ASCOLARI, 2009, p. 162). Agrega-se a civilidade como disciplina que visa a internalização das normas e posturas sociais e a gestão da disciplina coletiva. "Neste sentido, quando se impõe a necessidade de pensar a educação do povo, a matriz pedagógica [...] se condensa práticas como o livro texto, a educação do corpo, a disciplina e a atividade intensa e repetitiva" (VIDAL; ASCOLARI, 2009, p. 163) e, portanto, se sobressaem princípios como a moral, a virtude e a ordem. Frente a essa demanda o Estado, no Brasil e na Argentina, chama para si a responsabilidade pela educação das crianças e jovens, buscando formar trabalhadores mais eficientes e obedientes. 
No subeixo Construir a nação, formar o cidadão e universalizar a escola, as autoras destacam que a Revolução de Maio de 1810 marca o início da criação da nação argentina. Já no Brasil, o Ato Institucional de 1834 “[...] redundou na difusão de competências em relação à instrução pública [...]”, todavia, a universalização da escola se deparou com “[...] os limites impostos pela diversidade de conjunturas econômicas e pelas particularidades das configurações políticas das distintas regiões do país" (VIDAL; ASCOLARI, 2009, p. 167). A civilização e disciplinarização, relatadas nas inúmeras outras reformas e políticas mencionadas, refletem nos deveres dos alunos com um viés voltado à:

\begin{abstract}
Asseio dos corpos e dos trajes, pontualidade, delicadeza, urbanidade, respeito e obediência aos superiores, bondade, amizade e sinceridade que compunham o código de honra escolar, indicando a permanência de antigos parentescos entre a higiene e a moral, dos vínculos entre a decência e o decoro exteriores e as virtudes do homem interior. Assentadas em sólidas bases científicas, as normas escolares pretender velar pela harmonia e pelo equilíbrio do trabalho escolar, de modo que essa ordem se grave na mente dos alunos de modo indelével. $\mathrm{Na}$ escola argentina, como na brasileira, as exigências de moderação e equilíbrio marcam as formas de organizar o trabalho escolar. (VIDAL; ASCOLARI, 2009, p. 179).
\end{abstract}

A caligrafia, as posturas adotadas por cada gênero, os exercícios físicos e intelectuais desenvolvidos na escola, neste sentido, apresentavam a busca pela civilidade e educação dos corpos infantis sob um modelamento com vistas à atividade e eficiência, ao são e ao estético. As trajetórias do Brasil e da Argentina no que tange essa temática são marcadas por similitudes, peculiaridade e hibridizações, pois ora mesclam propostas educacionais, ora desenvolvem os seus próprios modelos. E isso recai na propagação cultural de grupos sociais e das relações de poderes.

O sexto capítulo Reformas para modernizar a universidade: as visões de Risieri Frondizi e Anísio Teixeira, de Sandra Carli e Bernardo J. Oliveira, enfoca a visão desses dois pensadores sobre a educação superior na Argentina e no Brasil, destacando que a reestruturação das universidades foi a principal pauta da reunião do Conselho de Educação Superior das Repúblicas Americanas, reunido no Chile, em 1960. Risieri Frondizi e Anísio Teixeira estiveram neste evento e foram condutores de muitas propostas de mudanças para seus países. As ideias de ambos "[...] levam a uma direção comum na reforma universitária, como uma oposição frontal à ideia de universidade como local de cultivo da tradição e da erudição, e a defesa ativa da universidade como lugar da produção de conhecimento" (VIDAL; ASCOLARI, 2009, p. 206). 
Neste capítulo os autores abordam a biografia de Anísio e Risieri e, consequentemente, traçam um paralelo entre suas ideias e uma Breve história do ensino superior na Argentina e no Brasil, destacando, posteriormente a Modernização da Universidade. Segundo os autores, as ideias dos dois pensadores se alinhavam a defesa de que "[..] o conhecimento é concebido como um instrumento. Contrariamente a ideia de erudição e de acervo, o conhecimento deveria ser pensado com base nas necessidades do presente e das possibilidades futuras, em termos de desenvolvimento social" (VIDAL; ASCOLARI, 2009, p. 212). Anísio defendia a ideia de um saber vivo e não se um saber morto. Já Risieri buscava aprofundar o pensamento reformista, denunciando o caráter anacrônico da universidade que seguia o modelo colonial (VIDAL; ASCOLARI, 2009).

Por outro lado, as visões argentina e brasileira destoavam em relação ao entendimento de uma universidade "popular". Enquanto a primeira defendia uma que uma elevação intelectual das massas não era função última da universidade, mesmo não concebendo um restritivo de ingresso nas academias, à segunda era vanguarda em extensão universitária e difusão do conhecimento. A Argentina teve supremacia de vagas na educação superior em relação ao Brasil, pois para o segundo o crescimento de vagas de forma acelerada e desordenado era um problema. Todavia, dessas concepções de que a mudança era necessária que nasce a reforma universitária, marcada por resistências e por conflitos, mas que induz a um novo modelo de construção do ensino superior no Brasil e na Argentina. Nos dois países, “[...] a modernização e a reforma da universidade, as influências e resistências que enfrentaram ganharam contornos muitos semelhantes. E, neste sentido, podemos dizer que ambos foram homens representativos do seu tempo" (VIDAL; ASCOLARI, 2009, p. 235).

Outro ponto que merece comentário na diferenciação das experiências de Risieri e Anísio é o lugar onde atuaram e pensaram as reformas. Risieri revela uma visão integral da reforma, mas centrada numa instituição específica, a UBA. Já a atuação de Anísio Teixeira em instituições mais abrangentes, como a secretária da educação, Capes e Inep, deram a ele uma visão mais ampla da organização da administração do sistema educacional como um todo. [...] as reformas [...] delineara modalidades, estilos, problemas e horizontes de modernização das universidades e se tornaram paradigmas em muitos aspectos. (VIDAL; ASCOLARI, 2009, p. 235).

Por fim, o sétimo capítulo, denominado Ditaduras militares argentina e brasileira: colaborações culturais em educação na década de 1970 e século XX, foi escrito por Carolina Kaufmann e Maria do Carmo Martins. As autoras discorrem sobre a educação nos dois países durante as suas ditaduras. Inicialmente, elas pontuam que os regimes ditatoriais se estabeleceram na Argentina entre 1976 e 1983 e no Brasil entre 1964 e 1985 e adotavam 
múltiplas práticas questionáveis referentes à repressão e eliminação da subversão e tendo como princípio básico a Doutrina da Segurança Nacional.

Na Argentina a pedagogia deste período articula-se à Pedagogia Autoritária, ou seja, destacavam-se:

\begin{abstract}
Jornadas universitárias e diferentes reuniões científicas, nas quais apresentavam e discutiam às tendências para a pedagogia autoritária e de traço autoritário; Autores argentinos dedicados à escrita de obras, que apresentavam, por meio de sínteses e rearticulações, os autores clássicos da educação personalizada autoritária; Formação de "quadro de pessoal", por meio do Plano Nacional de Aperfeiçoamento docente [...]; Constituição de equipes de pesquisadores, comissões e grupos acadêmicos alinhados ao governo militar. (VIDAL; ASCOLARI, 2009, p. 245).
\end{abstract}

No Brasil, ocorria o fortalecimento de conselhos e comissões para dar legalidade social ao regime, criação de comissões de avaliações de livros educativos e de currículos em diferentes níveis, trazendo unicidade a visão política, assim como propondo tentativas de construção de currículos e de discursos pedagógicos com vistas à seleção cultural (VIDAL; ASCOLARI, 2009). As disciplinas e ordem cívicas eram mantidas como forma de difusão dos ideais do sistema da época e "[...] as políticas educativas, levadas a cabo no ensino técnico argentino e na educação básica, propedêutica, brasileira, responderam, em princípio, às prescrições da política geral das Forças Armadas” (VIDAL; ASCOLARI, 2009, p. 257), isto é, a predominância de uma visão ocidental cristã, naturalizada na sociedade.

Essa retomada histórica, traçada pelos autores ao longo dos sete capítulos do livro, permite refletir e compreender de forma mais aprofundada a História da Educação no Brasil e na Argentina, bem como compreender como os contextos políticos, sociais, econômicos interferem na organização do espaço geográfico dos dois países do Cone Sul por meio da educação. A educação é nitidamente uma fonte de transformação ou manutenção de ideais de uma sociedade e, portanto, tem influência direta na compreensão das dinâmicas territoriais dos países. Por isso, ao buscar compreender a organização de um território se deve, imprescindivelmente, analisar os caminhos e as políticas que nortearam os seus sistemas educativos, pois tal análise é central aos objetivos e padrões de sociedade que daí emergem.

Logo, o livro Reformas educativas no Brasil e na Argentina: ensaios de história comparada da educação (1820-2000) pode contribuir muito com geógrafos e professores de Geografia, na medida em que permite compreender a relação entre os sistemas educativos, as reformas educacionais e o contexto histórico do Brasil e da Argentina no período de recorte da análise, bem como as origens dos projetos subsequentes as análises traçadas no livro. 
Portanto, ao pensarmos o Cone Sul, ou mesmo a América Latina como um todo, passa a ser extremamente necessário analisarmos em profundidade a evolução dos modelos e padrões educativos, pois, somente assim, teremos uma visão completa dos porquês e por quais motivos muitos contextos sócio-políticos-econômicos se tornam latentes em nossos países. Estudar a educação e sua história, dessa maneira, é muito relevante a Geografia e essa abordagem não pode ser negligenciada quando se busca uma compreensão mais abrangente, complexa e fiel ao objeto de estudo de nosso ciência. 